\title{
Article \\ Traffic and Energy Consumption Modelling of Electric Vehicles: Parameter Updating from Floating and Probe Vehicle Data
}

\author{
Antonello Ignazio Croce ${ }^{1}\left(\mathbb{D}\right.$, Giuseppe Musolino $^{2, *} \mathbb{(}$, Corrado Rindone ${ }^{2}\left(\mathbb{D}\right.$ ) and Antonino Vitetta ${ }^{2}$ \\ 1 Dipartimento di Agraria, Università degli Studi Mediterranea di Reggio Calabria, Feo di Vito, \\ 89122 Reggio Calabria, Italy; antonello.croce@unirc.it \\ 2 Dipartimento di ingegneria dell'Informazione, delle Infrastrutture e dell'Energia Sostenibile, Università degli \\ Studi Mediterranea di Reggio Calabria, Feo di Vito, 89122 Reggio Calabria, Italy; \\ corrado.rindone@unirc.it (C.R.); vitetta@unirc.it (A.V.) \\ * Correspondence: giuseppe.musolino@unirc.it; Tel.: +39-096-5169-3272
}

check for updates

Citation: Croce, A.I.; Musolino, G.; Rindone, C.; Vitetta, A. Traffic and Energy Consumption Modelling of Electric Vehicles: Parameter Updating from Floating and Probe Vehicle Data. Energies 2022, 15, 82. https://doi.org/10.3390/en15010082

Academic Editor: Balázs Németh

Received: 20 November 2021

Accepted: 16 December 2021

Published: 23 December 2021

Publisher's Note: MDPI stays neutral with regard to jurisdictional claims in published maps and institutional affiliations.

Copyright: (C) 2021 by the authors. Licensee MDPI, Basel, Switzerland. This article is an open access article distributed under the terms and conditions of the Creative Commons Attribution (CC BY) license (https:// creativecommons.org/licenses/by/ $4.0 /)$.

\begin{abstract}
This paper focuses on the estimation of energy consumption of Electric Vehicles (EVs) by means of models derived from traffic flow theory and vehicle locomotion laws. In particular, it proposes a bi-level procedure with the aim to calibrate (or update) the whole parameters of traffic flow models and energy consumption laws by means of Floating Car Data (FCD) and probe vehicle data. The reported models may be part of a procedure for designing and planning transport and energy systems. This aim is to verify if, and in what amount, the existing parameters of the resistances/energy consumptions model calibrated in the literature for Internal Combustion Engines Vehicles (ICEVs) change for EVs, considering the above circular dependency between supply, demand, and supply-demand interaction. The final results concern updated parameters to be used for eco-driving and eco-routing applications for design and a planning transport system adopting a multidisciplinary approach. The focus of this manuscript is on the transport area. Experimental data concern vehicular data extracted from traffic (floating car data and probe vehicle data) and energy consumption data measured for equipped EVs performing trips inside a sub-regional area, located in the Città Metropolitana of Reggio Calabria (Italy). The results of the calibration process are encouraging, as they allow for updating parameters related to energy consumption and energy recovered in terms of EVs obtained from data observed in real conditions. The latter term is relevant in EVs, particularly on urban routes where drivers experience unstable traffic conditions.
\end{abstract}

Keywords: sustainable mobility; smart energy; energy consumption models; traffic flow models; internal combustion engines vehicles (ICEVs); electric vehicles (EVs); floating car data (FCD); probe vehicle data

\section{Introduction}

Mobility of people and goods inside a smart energy environment is a cross-cutting issue to be addressed in order to help achieve the 2030 agenda for sustainable development.

Transport infrastructure and services are means allowing people and business to access destinations (e.g., workplaces, schools, markets) in order to perform activities. At the same time, these means require natural, economic and financial resources. Among them, energy resources are crucial, in order to reach sustainability $([1,2])$.

Electric Vehicles (EVs) play a relevant role in sustainable mobility. In recent years, there has been an increasing use of EVs in the mobility of people and goods, and they are replacing traditional internal combustion engine vehicles (ICEVs). This evolution has several implications in the so-called tank-to-wheel process.

This paper focuses on energy consumption for mobility. Particular attention is devoted to the estimation of energy consumption of EVs by means of models derived from traffic flow theory and vehicle locomotion laws. The objective is to calibrate (or update) the whole parameters of traffic flow models, vehicle locomotion laws and energy consumption by means of Floating Car Data (FCD), and probe vehicle data. 
The transport models considered in this paper are a part of the more general models for the supply transport sub-system. The supply models, together with demand and the demand-supply interaction models are adopted for the analysis, design, and planning modelling transport and smart energy systems. The aim of this paper is relative to the transport medialization, with the aim to design the system a priori in order to reach sustainability via a multi-disciplinary approach.

The calibration process at each level (I. FCD and II. Probe) is developed with an optimization framework inside a Specification-Calibration-Validation (SCV) approach. The Specification (S) adopts the consolidated energy consumption models, which have a mixed static/dynamic nature. The Calibration (C) is carried out using a weighted GLS (Generalized Least Square) estimator, sequentially combining the energy components related to consumption and to recovery. The Validation (V) is carried out evaluating statistical indicators to verify the quality of the model.

The innovations reported in this paper mainly concern two elements (more details are reported in Section 2.4). The first concerns the updating of the traditional parameters of energy consumption models for EVs, estimated in the past for ICEV vehicles. The second concerns the minimization of costs necessary to build the above models, as the calibration is executed by means of FCD and probe vehicles data.

The results of the calibration process allow for updating parameters related to energy consumption and energy recovering in terms of EVs. The recovery term is relevant in the case of Evs, especially in urban areas, where drivers experience unstable traffic conditions (stop-and-go), rather than in extra-urban areas, where drivers travel in stable traffic conditions (constant speed).

The calibrated parameters could allow to update the explicit relationships of Evs' energy consumption and traffic conditions in terms of circular dependency between: (a) EVs' energy consumption, times and costs (supply); (b) users' behaviour and choice (demand); (c) traffic flow on links and paths (supply-demand interaction).

The remaining part of the paper is structured as follows. Section 2 presents a state of the art concerning the main issues of the paper: data, speed functions, and energy consumption models. The proposed framework is presented in Section 3. Section 4 reports the experimental results. Conclusions and developments are reported in the last section.

\section{State of the Art and Research Contribution}

The state of the art concerns the main issues of the paper: data (Section 2.1); speed functions (Section 2.2); energy consumption models (Section 2.3). Section 2.4 reports the research contribution in relation to the existing literature.

\subsection{Data}

ICT applications for mobility and automotive markets (e.g., mobile phones, GPSs, onboard vehicles equipment) allow for the collection of a large amount of potentially valuable data on travel patterns, transport networks and energy consumption of vehicles ([3] and the included references). The possibility to replace or integrate data coming from traditional surveys with big-data depends on the ability to select, filter and process them ([4]).

The main big-data sources are mobile phones, smart cards, GPS and Point Of Interests (POIs). GPS and Bluetooth data are widely used in mobility applications and in travel time estimation due to their high spatial-temporal resolution, such as monitoring private passenger and freight vehicles (Floating Car Data, FCD). Today, their potentialities in providing positions, speeds and accelerations, and in general, spatio-temporal trajectories of road vehicles are commonly recognized ([5]). They could support the building of Transport System Models (TSMs), which are composed of three modelling elements ([6]): Transport Supply (TS) models, Travel Demand (TD) models and Transport Supply-Travel Demand (TS-TD) models.

As far as concerning TS, [7] proposed a graph-based approach to elaborate data about vehicle trajectory, in order to extract general patterns about mobility. Oloo, F., et al. [8] 
elaborated GPS data related to trajectories of motorcycle taxis with a semi-automatic procedure with the aim to model rural-level road networks in Kenya. Croce, A.I., et al. [4] proposed a procedure that uses FCD and traditional data to support the processes of zoning and graph building. The proposed procedure provides benefits in the network model forecasting capabilities and reduces the costs connected to traditional surveys. Some authors elaborate GPS data to obtain performance measures (e.g., travel time, average speeds) of specific road segments ([9]). Pirra, M., et al. [10] proposed a measurement method of congested travel times, integrating data from GPS and from traffic conditions. As far as concerns TD (and TS-TD), big data (i.e., FCD, CDR) are used, sometimes in synergy with traditional data, to estimate travel behaviour or origin-destination flow matrices. Wang, J., et al. [11] investigated driving behaviour through FCD, which are converted into passengers' ring and chain trips. Nuzzolo, A., et al. [12] processed taxi data (FCD) in order to assess taxi services in Rome. These data were converted into data useful to estimate within-day and day-to-day service demand, considering the main trips' characteristics (e.g., origin, destination and travel time).

\subsection{Speed Functions}

The literature on speed functions cannot be dissociated from the more comprehensive one related to Transport System Models (TSMs), in particular, to the three modelling components above specified.

In relation to TS, the network approach is the one commonly used in literature ([6]), where the supply is modelled with nodes, links and cost functions. According to their level of aggregation, cost functions may be specified with speed-density or time-flow relationships (in the aggregate case), or with car-following, lane-changing and gap-acceptance models (in the disaggregate case).

As far as concerns aggregate cost functions, there is a long research history concerning the definition of relationships (Traffic Flow, TF, models) between average vehicular speed, flow and density in order to describe traffic conditions on a link, a class of links, and in general on a network. In the link case, several specifications were proposed in the past able to represent steady-state conditions, which range from mono-regime to multi-regime models ([13], and the references included). In the network case, there is a more recent line of research that assumes the existence of a relationship between speed, flow and density at network level, called Network Macroscopic Fundamental Diagram (NMFD) ([14], and the references included).

In relation to TD, it is commonly used in literature the multi-step approach, simulating the trip purpose, departure time, origin, destination, mode and path of users $([6,15] ;)$. Travel demand models can be classified into two main categories: not-behavioural models or behavioural models. The first category is general based on gravitational-entropy principles, while the second one has random utility, fuzzy or quantum utility as background theories ([16]).

In relation to TS-TD, traffic assignment models consider the interaction between travel demand and transport network, estimating costs (or disutilities) and traffic flows on the network. If the available supply (transport facilities and services) is limited, congestion costs arise. Traffic assignment models can be classified according to different criteria: the criterion of aggregation of cost functions categorizes models into macroscopic and microscopic; the second criterion regards the static vs. dynamic nature of models $([6,17])$.

\subsection{Energy Consumption Functions}

Many economic studies predict in the next future that the automotive market will be covered by EVs in several configurations (i.e., hybrid plug-in or not, extended range). ([18], and the references included). Some elements are currently under development in order to support a large scale diffusion of EVs:

(i) batteries; 
(ii) charging stations in term of location, infrastructure $([19,20]$, and the references included);

(iii) energy consumption connected to vehicle performances and drivers' behaviour ([21-23]);

(iv) energy recovered with the brake system ([24]). The recovered energy is relevant in EVs: it is more evident on urban routes, where drivers experience instability conditions (frequent stop-and-go), rather than on freeways, where drivers travel in more stable conditions ([25]). The values of wheels-to-battery regenerative efficiency, defined as the portion of energy dissipated during deceleration and downhill which is recovered with regenerative braking system, range from 0.59 to 0.84 in literature. A literature review of different calculated values is presented in [21].

As concerns energy consumption models, two classification criteria can be adopted ([21, 26,27];). The first criterion considers forward models, that estimate energy from the engine to the wheels; and backward models, that estimate energy from the wheels to the engine. The second criterion is based on the level of temporal aggregation. Models may be steadystate (or aggregate) and dynamic (disaggregate). Steady-state models need fewer input data (e.g., average link speed, consumption per unit of travelled distance), than dynamic models (e.g., instantaneous speed/traction profile of vehicle). However, the former ones provide aggregate results that do not take into account the variability of driver behaviour, vehicle and infrastructure characteristics.

\subsection{Research Contribution}

The research contribution of the paper regards the integration of energy consumption models, FCD and experimental data in a proposed framework in order to pursue two objectives.

(i) The first concerns the updating of the traditional parameters of energy consumption models for EVs, estimated in the past for ICEV vehicles ([28]) at a macroscopic level. This could allow adopting the energy consumption model inside the static and day-to-day dynamic assignment models in order to consider the circular dependency between travel demand and transport network. The objective to estimate continuous profiles of speed, acceleration and energy consumption of EVs, to be used in microscopic dynamic traffic assignment models, is out of the scope of this research. The authors adopt in this research aggregated profiles of speed, acceleration and energy consumption of Evs, to be used in macroscopic (static) traffic assignment models.

(ii) The second concerns the minimization of costs necessary to build the above models. Surveys to obtain traffic data (vehicular flows, densities), vehicles cinematic (speeds and accelerations) and energy consumption (fuel, electricity consumption) are expensive. Real-time and/or off-line big-data gives a lot of historical information in the space and in the time about passengers' mobility and freight transported. This data cannot be directly used for system forecast. The data have to be used for the transport system state indicators estimation and for the integration with the transport models. The combination of big-data and experimental ones could lead to relevant benefits in terms of model building results.

(i and ii.) The paper can be considered as an example of a possible application for validate models for traffic flow and energy consumption in real context, updating previous and/or literature model specification and parameters values.

\section{Proposed Framework}

The proposed framework (Figure 1) allows to update the parameters of traffic flow models and energy consumption models by means of a SCV procedure from FCD and experimental data deriving from probe vehicle monitoring.

The framework has three components, as presented below.

The Specification (S), reported in Section 3.1, where models are specified; they allow to estimate performances (estimated variables) from parameters of literature (initial parame- 
ters) by means of system modelling. The specification adopts traditional models existing in the literature. The energy consumption models have a mixed static/dynamic nature. The static component allows for estimating the average values of vehicular speed and acceleration on the links, or on classes of links, of a road network. The (quasi-)dynamic component allows for estimating the energy consumption of an EV in a discrete spatial-temporal domain, according to the average values of speed, acceleration and traction/resistance. The energy consumption of EVs combines models derived from: vehicles locomotion laws, to estimate the resistances acting on a vehicle in motion and then to estimate energy consumption; traffic flow theory, to estimate the interactions among vehicles inside the road facilities.

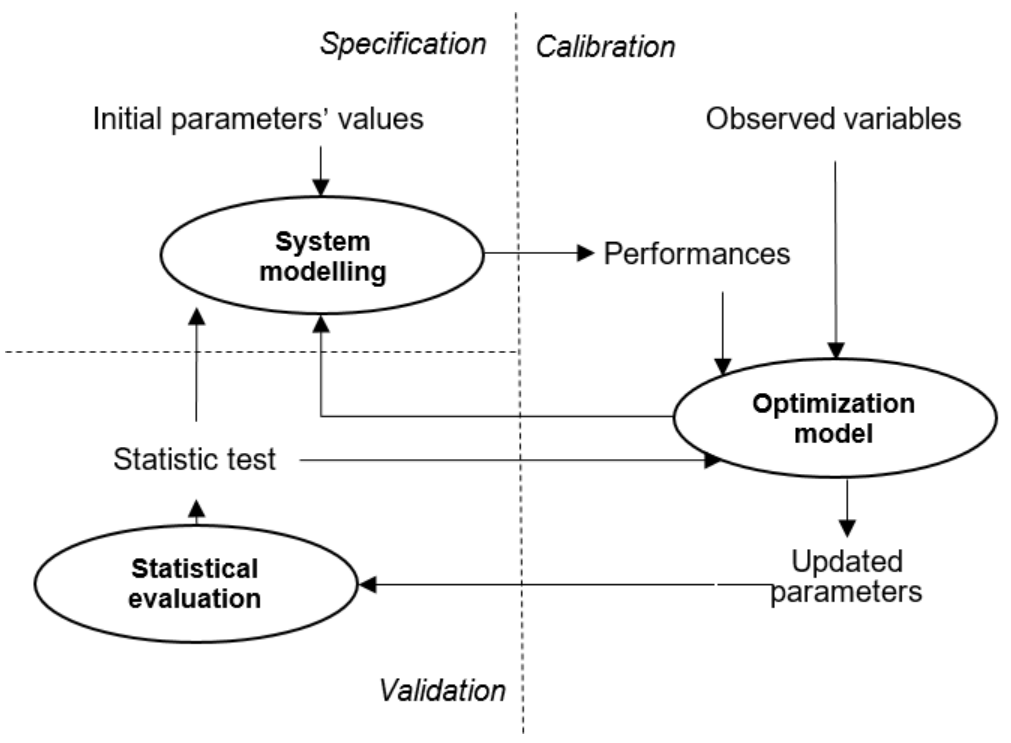

Figure 1. Specification-Calibration-Validation procedure.

The Calibration (C), reported in Section 3.2, where an optimization model allows to updating parameters of traffic flow and/or energy consumption models (updated parameters) by means of experimental traffic and energy consumption data (observed variables). The calibration is carried out using a weighted GLS (Generalized Least Square) estimator, sequentially combining the energy components related to consumption and to recovery. Data used for the model calibration belong to two categories: floating car data available from ICT (i.e., GPS) devices, that provide information about spatial-temporal positions of equipped vehicles; data deriving from probe EVs traveling in a real road network.

The Validation (V), reported in Section 3.3, where informal and formal statistic tests for ending the procedure or come back at specification or calibration level. The validation is carried out evaluating statistical indicators in order to confirm the quality of the model or to give indications that the SCV procedure has to come back at calibration or specification level.

There are several areas of application of the proposed framework (Table 1): TD models, TS models, TF models, Energy Consumption (EC) models.

As far as concerns the initial parameters of all the models, they generally are the ones that have been already calibrated in other similar contexts (available in literature).

The SCV procedure for TSMs' building is commonly used in literature, while it is not common the combined usage of FCD and probe vehicle data. The aim is to show the potentialities connected to FCD and probe data in calibrating model parameters. In particular, the focus is on speed flow and energy consumption functions, this is the reason of the disaggregation of TS area in Table 1. 
Table 1. Areas of application of the proposed framework and parameters calibration from FCD and from probe vehicles.

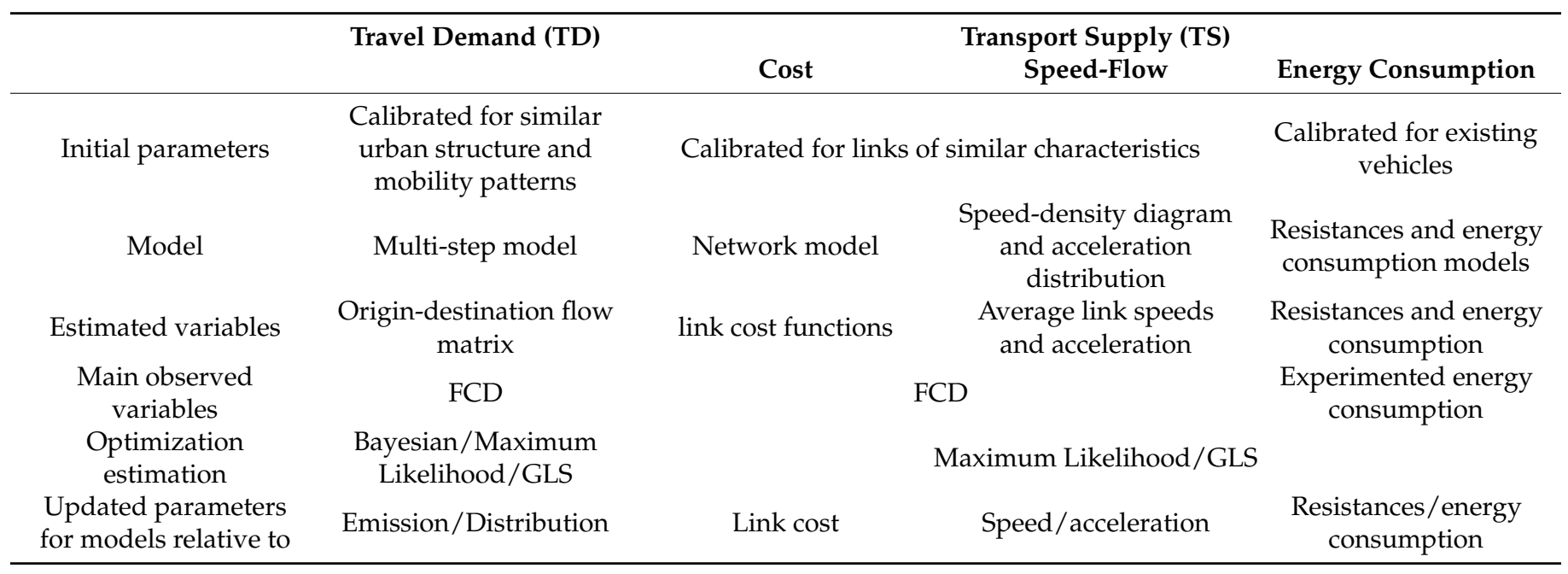

\subsection{Speed Functions}

The functions' specifications (S), used for TS modelling in static and day-to-day dynamic assignment, belong to two classes:

- (vehicular) speed functions (TF, Section 3.1.1);

- $\quad$ energy consumption functions (EC, Section 3.1.2).

\subsubsection{Speed Functions}

The instantaneous speed of a vehicle depends on space $s$ and time $t$ by means of other fundamental traffic flow variables, such as density, $\mathrm{k}=k(\mathrm{~s}, \mathrm{t})$ and flow, $\mathrm{q}=q(\mathrm{~s}, \mathrm{t})$, and a vector of parameters $\beta_{\mathrm{v}}$ to be calibrated.

Two assumptions can be adopted:

(a) the traffic flow variables depend on each other, and only density $\mathrm{k}=k(\mathrm{~s}, \mathrm{t})$ could be assumed as reference;

(b) the variables k (density) and q (flow) can be assumed stationary in a reference time interval (assumed equal to $t^{*}$ ) and space interval (assumed equal to $\mathrm{s}^{*}$, i.e., link, or class of links) and assume values (density) $\mathrm{k}^{\mathrm{t}^{*}, \mathrm{~s}^{*}}$ and (flow) $\mathrm{q}^{\mathrm{t}^{*}, \mathrm{~s}^{*}}$. According to the above assumption, the speed function, $v()$, depends on:

$$
\mathrm{v}^{\mathrm{t}^{*}, \mathrm{~s}^{*}}=v\left(\beta_{v}\left(\mathrm{k}^{\mathrm{t}^{*}, \mathrm{~s}^{*}}, \mathrm{q}^{\mathrm{t}^{*}, \mathrm{~s}^{*}}\right), \mathrm{k}^{\mathrm{t}^{*}, \mathrm{~s}^{*}}\right)
$$

where $\beta_{v}()$ is the vector of the speed function parameters.

\subsubsection{Energy Consumption Functions}

The total resistance acting on a vehicle (obtained as the sum of rolling resistance, aerodynamic resistance, slope resistance), in the time and space interval $\mathrm{t}^{*}, \mathrm{~s}^{*}$, may be expressed as a function, $r()$ :

$$
\mathrm{r}_{\text {tot }}{ }^{\mathrm{t}^{*}, \mathrm{~s}^{*}}=r\left(\mathrm{x}, \mathrm{v}^{\mathrm{t}^{*}, \mathrm{~s}^{*}}, \alpha\right)
$$

where

$\mathrm{x}$ is the vector of vehicle attributes (i.e., mass $\mathrm{x}_{\mathrm{m}}$, coefficient of aerodynamic shape, $\mathrm{x}_{\mathrm{a}}$ ); $\mathrm{v}^{\mathrm{t}^{*}, \mathrm{~s}^{*}}$ is the speed in the time and space interval $\mathrm{t}^{*}, \mathrm{~s}^{*}$; $\alpha$ is the vector of resistances' parameters. 
The vehicle is subject also to the inertial and traction forces. The inertial force $r_{i}$, in the time and space interval $t^{*}, \mathrm{~s}^{*}$, is equal to:

$$
r_{i} t^{*}, s^{*}=x_{m} \times a^{t^{*}, s^{*}}=x_{m} \times \beta_{a}
$$

with

$\mathrm{x}_{\mathrm{m}}$, mass of the vehicle;

$\mathrm{a}^{\mathrm{t}^{*}, \mathrm{~s}^{*}}$, acceleration evaluated in the time and space interval $\mathrm{t}^{*}, \mathrm{~s}^{*}$.

The acceleration is a cinematic parameter $\beta_{\mathrm{a}}$ to be calibrated. It can be assumed: $\beta_{\mathrm{a}}=\mathrm{a}^{\mathrm{t}^{*}, \mathrm{~s}^{*}}$. For calibration purpose, a vector, $\beta_{\mathrm{a}}$, of accelerations can be defined considering positive (acceleration) or negative (deceleration) phases.

The traction force, $\mathrm{n}^{\mathrm{t}^{*}, \mathrm{~s}^{*}}$, is the force that the engine gives to the wheels in the time and space interval $t^{*}, \mathrm{~s}^{*}$. It has to be lower that the adhesion force acting between the tyre and the road surface. It is regulated by the driver in the space and in the time.

According to the Newton principle:

$$
\mathrm{n}^{\mathrm{t}^{*}, \mathrm{~s}^{*}}=\mathrm{r}_{\mathrm{tot}} \mathrm{t}^{*}, \mathrm{~s}^{*}+\mathrm{r}_{\mathrm{i}} \mathrm{t}^{*}, \mathrm{~s}^{*}
$$

Several external factors related to the environment, vehicle and driver, not previously considered, could influence the forces in the real context (indicated with the symbol $\gamma$ ). For this reason, some parameters may be introduced in Equation (4):

$$
\mathrm{n}^{\mathrm{t}^{*}, \mathrm{~s}^{*}}=\gamma_{\mathrm{rt}} \times \mathrm{r}_{\mathrm{tot}} \mathrm{t}^{*}, \mathrm{~s}^{*}+\gamma_{\mathrm{in}} \times \mathrm{r}_{\mathrm{i}}^{\mathrm{t}^{*}, \mathrm{~s}^{*}}
$$

with

$\gamma_{\mathrm{rt}}$, parameter related to resistances (to be calibrated);

$\gamma_{\text {in, }}$ parameter related to inertia (to be calibrated).

Let:

- $\quad h$, is the path followed by the vehicle, composed by road links (belonging to a class) $\mathrm{s}^{*}$ of length $1_{\mathrm{S}^{*}}$;

- $\mathrm{n}^{\mathrm{t}^{*}, \mathrm{~s}^{*}} \cdot 1_{\mathrm{s}^{*}}$ is the energy at the wheels necessary for the motion of a vehicle on a road $\operatorname{link} \mathrm{s}^{*}$;

- $\quad \mathrm{e}_{\mathrm{h}}$ is the energy consumed by the engine of a vehicle along a road path $\mathrm{h}$;

- $\quad \mathrm{e}_{\mathrm{a}}$ is the energy consumption for the accessory installations (i.e., air conditioning);

- $\gamma_{\mathrm{t}-\mathrm{w}}$ is the efficiency parameter related to energy consumption (to be calibrated);

- $\gamma_{\mathrm{w}-\mathrm{b}}$ is the efficiency parameter related to energy recovered (to be calibrated). By considering a time and space interval $\mathrm{t}^{*}, \mathrm{~s}^{*}$, three cases can be introduced:

- Case I: the traction force is greater than zero, $\mathrm{n}^{\mathrm{t}^{*}, \mathrm{~s}^{*}}>0$ (Equations (4) or (5)), and the vehicle consumes energy:

$$
\mathrm{e}_{\mathrm{h}}=\mathrm{e}_{\mathrm{a}}+\left(\Sigma_{\mathrm{s} * \in \mathrm{h}} \mathrm{n}^{\mathrm{t}^{*}, \mathrm{~s}^{*}} \times 1_{\mathrm{s}^{*}}\right) / \gamma_{\mathrm{t}-\mathrm{w}}
$$

- Case II: the traction force is lower than zero, $\mathrm{n}^{\mathrm{t}^{*}, \mathrm{~s}^{*}}<0$ (Equations (4) or (5)), and the vehicle recovers energy:

$$
\mathrm{e}_{\mathrm{h}}=\mathrm{e}_{\mathrm{a}}+\left(\Sigma_{\mathrm{s} * \in \mathrm{h}} \mathrm{n}^{\mathrm{t}^{*}, \mathrm{~s}^{*}} \times 1_{\mathrm{s}^{*}}\right) \times \gamma_{\mathrm{w}-\mathrm{b}}
$$

- $\quad$ Case III: the traction force is equal to zero, $\mathrm{n}^{\mathrm{t}^{*}, \mathrm{~s}^{*}}=0$ (it could be included in case II considering that $\mathrm{n}^{\mathrm{t}^{*}, \mathrm{~s}^{*}}=0$ ):

$$
\mathrm{e}_{\mathrm{h}}=\mathrm{e}_{\mathrm{a}}
$$


The vectors $\alpha$ (relative to vehicle resistances), $\beta$ (relative to the speed, $\beta_{\mathrm{v}}$, and acceleration, $\beta_{\mathrm{a}}$ ) and $\gamma$ (relative to the vehicle inertia and resistance and to energy efficiency) have to be calibrated.

The dependency of energy from the three classes of parameters is synthetically expressed in the following function, $e()$, that take into consideration Equations (1)-(5):

$$
\mathrm{e}=e(\alpha, \beta, \gamma)
$$

where $\mathrm{e}$ is the energy vector, with $\mathrm{e}_{\mathrm{h}}$ as generic component.

\subsection{Calibration}

The calibration (C) of the three class of parameters $\alpha, \beta$ and $\gamma$ could be executed according to two types of procedure: simultaneous or sequential.

As concerns the simultaneous calibration, the objective function to be minimized is expressed as:

$$
\begin{gathered}
\left.\left.\min \left(e(\alpha, \beta, \gamma)-\mathrm{e}^{*}\right)^{\mathrm{T}} \times\left(e(\alpha, \beta, \gamma)-\mathrm{e}^{*}\right)+\mathrm{w}_{1} \times \alpha-\alpha^{*}\right)^{\mathrm{T}} \times \alpha-\alpha^{*}\right)+ \\
\left.\left.\left.+\mathrm{w}_{2} \times \beta-\beta^{*}\right)^{\mathrm{T}} \times\left(\beta-\beta^{*}\right)+\mathrm{w}_{3} \times \gamma-\gamma^{*}\right)^{\mathrm{T}} \times \gamma-\gamma^{*}\right)
\end{gathered}
$$

where

- $\quad \mathrm{e}^{*}$ is the vector of observed consumed energy (the generic entry $\mathrm{h}$ is $\mathrm{e}^{*} \mathrm{~h}$ );

- $\quad \alpha *, \beta *$ and $\gamma^{*}(=1)$ the initial values of parameters obtained from the literature;

- $\mathrm{w}_{1}, \mathrm{w}_{2}$ and $\mathrm{w}_{3}$ the relative weight of the single terms in the objective function.

The objective function could be applied also assuming the relative weights equal to zero. As concerns the sequential calibration, one step for each of the three vectors of parameters is considered:

- $\quad$ first step: calibration of $\alpha$ ( $\alpha^{\mathrm{OPT}}$ is obtained), assuming the values for $\beta$ and $\gamma$ given by literature;

- $\quad$ second step: calibration of $\beta$ ( $\beta^{\mathrm{OPT}}$ is obtained), assuming the value $\alpha^{\mathrm{OPT}}$ and $\gamma$ given by literature;

- $\quad$ third step: calibration of $\gamma\left(\gamma^{\mathrm{OPT}}\right.$ is obtained), assuming the value $\alpha^{\mathrm{OPT}}$ and $\beta^{\mathrm{OPT}}$.

As an example of the second step, the specification of the objective function for calibration of $\beta_{\mathrm{v}}$ :

$\min \left(v\left(\beta_{v}\left(k^{t^{*}, s^{*}}, q^{t^{*}, s^{*}}\right), k^{t^{*}, s^{*}}\right)-v^{*}\right)^{T} \times\left(v\left(\beta_{v}\left(k^{t^{*}, s^{*}}, q^{t^{*}, s^{*}}\right), k^{t^{*}, s^{*}}\right)-v^{*}\right)+w_{\beta} \times\left(\beta_{\mathrm{v}}-\beta_{\mathrm{v}}^{*}\right)^{T} \times\left(\beta_{\mathrm{v}}-\beta_{\mathrm{v}}^{*}\right)$

where

- $\quad v()$ is the vector of estimated speed with the model;

- $\mathrm{V}^{*}$ is the vector of observed speed;

- $\quad \beta_{\mathrm{v}}{ }^{*}$ is the initial vectors values of parameters obtained from the literature;

- $\mathrm{w}_{\beta}$ is a relative weight (it could be assumed equal to zero).

As an example of the third step, the specification of the objective function for calibration of $\gamma$ :

$$
\min \left(e\left(\alpha^{\mathrm{OPT}}, \beta^{\mathrm{OPT}}, \gamma\right)-\mathrm{e}^{*}\right)^{\mathrm{T}} \times\left(e\left(\alpha^{\mathrm{OPT}}, \beta^{\mathrm{OPT}}, \gamma\right)-\mathrm{e}^{*}\right)+\mathrm{w}_{1} \times\left(\gamma-\gamma^{*}\right)^{\mathrm{T}} \times\left(\gamma-\gamma^{*}\right)
$$

where

- $\quad \mathrm{e}^{*}$ is the vector of observed energy;

- $\quad \gamma^{*}$ is the initial vectors values of parameters obtained from the literature;

- $\mathrm{w}_{1}$ is a relative weight (it could be assumed equal to zero).

\subsection{Validation}

The Validation (V) allows to verify the reasonableness and significance of the estimated parameters, the model's capability to reproduce the observations and, if necessary, the 
hypotheses underlying the functional form assumed by the model. These activities can be carried out by means of the following statistical tests, starting from observations.

The most common statistical tests are formal and non-formal tests on calibrated parameters of the specified functions. Informal tests are based on the reasonableness of the signs of the calibrated parameters and on their mutual relationships. Formal tests belong to different groups. The first group of tests verifies the different hypotheses (if they exist) on the parameters' estimates, such as the t-student test on the single parameter or on couples of parameters, the chi-square test on the parameters' vector. The second group of tests are statistics on the goodness of fit of the model: for example, the rho-square statistic and the mean square error measure the model's capability to reproduce the observed data.

\section{Experimentation}

The experimentation was implemented to verify the proposed SCV approach in an experimental area, located in Calabria Region (Southern Italy). In particular, the experimental area (Figure 2) encompasses several towns close to Roccella Jonica, which attract great interest of tourists who arrive at the local port, called "Porto delle Grazie".

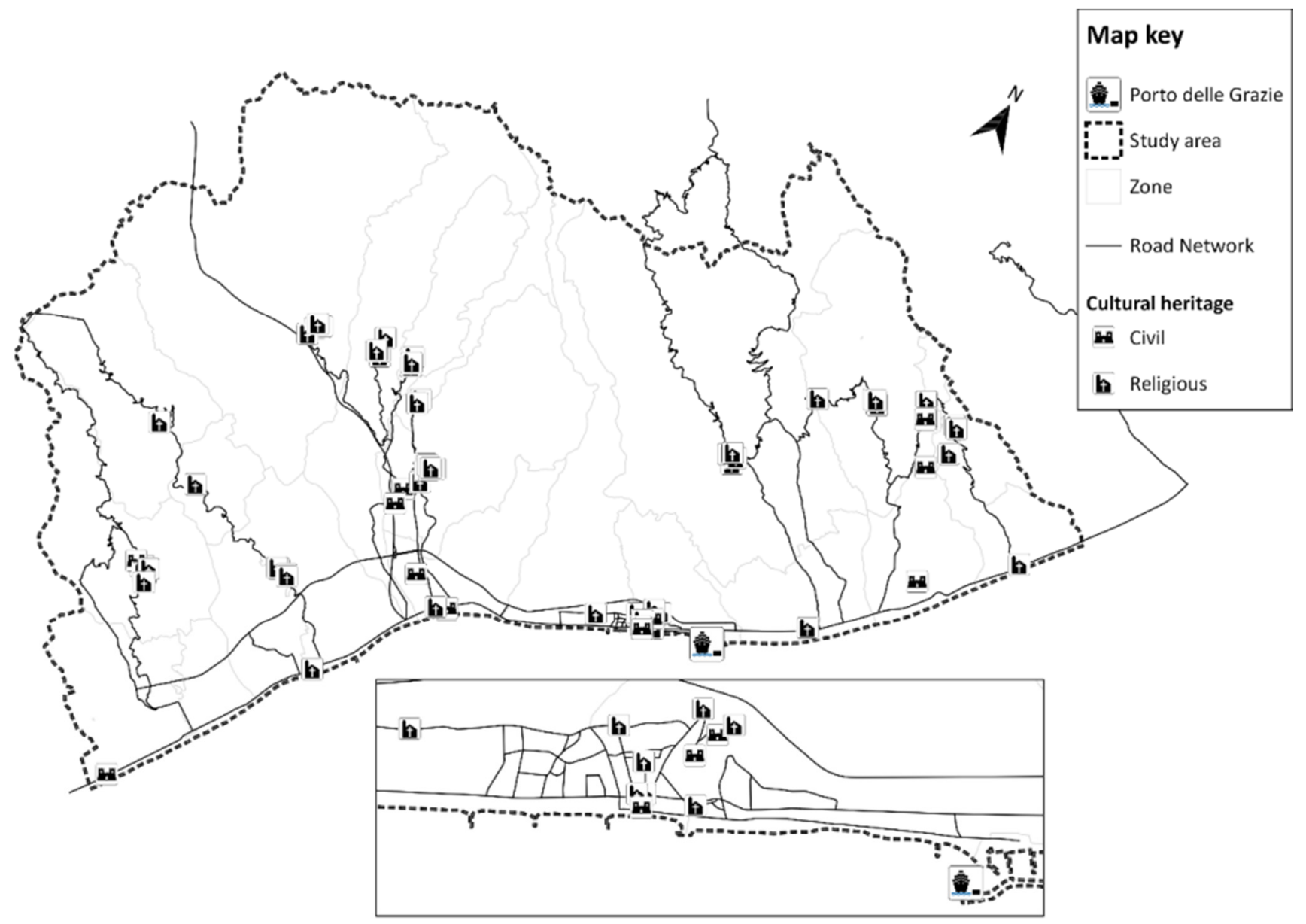

Figure 2. Study area with the port, the touristic destinations and the road network.

The analysis concerns the energy consumption of electric vehicles (EV), that offer transport services to tourists who arrive at the port and visit the touristic destinations inside the area. During the experimentation, EVs use an electricity charging station located inside the port. 


\subsection{Specification}

The speed function of Equation (2) is specified as a trapezoidal speed profile (Figure 3 as reference), with:

- $\quad \beta^{\mathrm{T}}=\left[\beta_{\mathrm{v}}^{\mathrm{T}} \beta_{\mathrm{a}}^{\mathrm{T}}\right]$ with $\beta_{\mathrm{v}}^{\mathrm{T}}=\left[\beta_{\mathrm{v} 1} \beta_{\mathrm{v} 2} \beta_{\mathrm{v} 3} \beta_{\mathrm{v} 4}\right]^{\mathrm{T}}$ the vector of parameters for speed and $\beta_{\mathrm{a}}^{\mathrm{T}}=\left[\begin{array}{ll}\beta_{\mathrm{a} 1} & \beta_{\mathrm{a} 2}\end{array}\right]^{\mathrm{T}}$ the vector of parameters for the acceleration;

- $\quad \beta_{\mathrm{v} 1}=\mathrm{v}_{\mathrm{m}}$ average speed, function of density and flow in congested link;

- $\quad \beta_{\mathrm{v} 2}, \beta_{\mathrm{v} 3}, \beta_{\mathrm{v} 4}$, percentage of link length where average vehicle speed is respectively increasing, constant, decreasing;

- $\quad \beta_{\mathrm{a} 1}(>0), \beta_{\mathrm{a} 2}(<0)$, respectively average acceleration and deceleration.

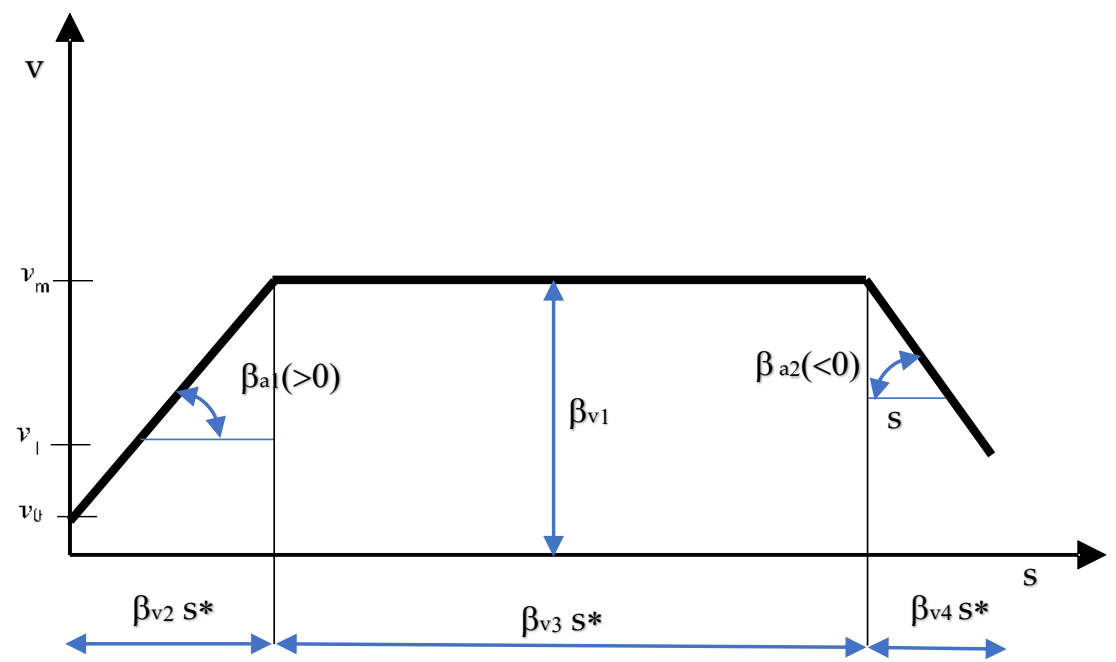

Figure 3. Trapezoidal average speed profile on link $\mathrm{s}^{*}$.

\subsection{Calibration}

The parameters $\beta$ and $\gamma$ are sequentially calibrated adopting the two correspond levels with two type data, as reported below.

I. FCD experimentation (Section 4.2.1), where parameters $\beta$ for speed and acceleration are calibrated using FCD. As well known, FCD do not provide information about energy consumption; therefore, the calibration of $\gamma$ with FCD experimentation was not possible.

II. Probe EV experimentation (Section 4.2.2), where parameters $\beta$ and $\gamma$ are calibrated using probe electric vehicles allowed to obtain measurements of kinematic (speed, acceleration) and energy quantities (energy consumption, energy recovery). The parameters of $\gamma$ have been calibrated, in their turn, through a double-stage calibration process.

The main characteristics of the adopted electric vehicle (vector $\mathrm{x}$ ) for the probe experimentation are: mass $1468 \mathrm{~kg}$, coefficient of aerodynamic shape 0.25 , front surface $1.5 \mathrm{~m}^{2}$.

It is assumed that the vector of the resistances parameters is constant: $\alpha=\alpha^{*}$.

\subsubsection{FCD experimentation}

The available data for FCD experimentation cover a portion of Calabria Region (Italy), including the experimental area, for two weeks (about 2.01 million vehicle positions). Preliminarily, the road graph was built in order to represent the main existing road facilities. The links of the road graph were classified into five classes according to their functional and geometric characteristics: length, width, number of lanes, average slope weighted by the distance ([4]):

Class 1: Freeway, extra-urban location, two lanes for each direction with separate carriageways (the average slope is $0.05 \%$ ); 
Class 2: Primary of type 1, extra-urban location, width greater or equal to $3.5 \mathrm{~m}$, one lane for each direction and average slope lower or equal to $0.5 \%$ (the average slope is $0.09 \%)$;

Class 3: Primary of type 2, extra-urban location, width greater or equal to $3.5 \mathrm{~m}$, one lane for each direction and average slope greater than $0.5 \%$ (the average slope is $2.03 \%$ );

Class 4: Extra-urban, width less than $3.5 \mathrm{~m}$, one lane for each direction (the average slope is $1.93 \%$ );

Class 5: Urban, one lane for each direction (the slope has average value $0.43 \%$ and high standard deviation).

From the available FCD (about 2.08 million), the data useful for the experimentation were obtained through a sequence of filtering operations:

- temporal filtering: selection of vehicle positions travelling during the weekdays (about 1.54 million);

- $\quad$ spatial filtering: elimination of vehicle positions outside the study area (0.17 million);

- cinematic filtering: selection of vehicle positions with speed greater than zero (0.13 million);

- $\quad$ topological filtering (or map matching): association of vehicle positions to the road network (0.06 million, which are $3.1 \%$ of the total points).

The data extracted from FCD allow to calibrate the vector $\beta$, by taking into account the classification of the road network.

The calibrated parameters $\beta_{\mathrm{v} 2}, \beta_{\mathrm{v} 3}, \beta_{\mathrm{v} 4}, \beta_{\mathrm{a} 1}$, and $\beta_{\mathrm{a} 2}$ are reported in Table 2 . The calibration was executed considering Equations (10) and (11), assuming the weights in the objective function equal to zero.

Table 2. Calibrated parameters of vector $\beta$ for each link class c.

\begin{tabular}{cccccc}
\hline & $\boldsymbol{\beta}_{\mathbf{v} \mathbf{2}}$ & $\boldsymbol{\beta}_{\mathbf{v} \mathbf{3}}$ & $\boldsymbol{\beta}_{\mathbf{v} \mathbf{4}}$ & $\boldsymbol{\beta}_{\mathbf{a} \mathbf{1}}(>\mathbf{0})$ & $\boldsymbol{\beta}_{\mathbf{a} \mathbf{2}}(<\mathbf{0})$ \\
\hline class c & $\mathbf{( 1 / \mathbf { m } )}$ & $\mathbf{( 1 / \mathbf { m } )}$ & $\mathbf{( 1 / \mathbf { m } )}$ & $\mathbf{( m / \mathbf { s e c } ^ { 2 } )}$ & $\mathbf{( \mathbf { m } / \mathbf { s e c } ^ { \mathbf { 2 } } )}$ \\
\hline 1 & 0.1 & 0.75 & 0.15 & 0.20 & -0.30 \\
2 & 0.06 & 0.83 & 0.11 & 0.20 & -0.20 \\
3 & 0.06 & 0.78 & 0.16 & 0.20 & -0.25 \\
4 & 0.07 & 0.88 & 0.05 & 0.20 & -0.20 \\
5 & 0.07 & 0.86 & 0.07 & 0.20 & -0.20 \\
\hline
\end{tabular}

The parameter $\beta_{\mathrm{v} 1}$ depends on $\mathrm{k}$ and $\mathrm{q}$, and it is estimated from a speed-density equation (Equation (1)) related to each link class, if FCD are not available.

Figure 4 reports a speed-density scatterplot of a link belonging to class $c=3$. The speed-density function is obtained from vehicle positions (FCD), by means of a procedure described in detail in ([29]). The procedure allows to estimate the average vehicular speed on link, v, and the average vehicular density on link, $\mathrm{k}$. for each time interval of the whole reference period. Then, the value of speeds and density are further averaged between all links belonging to each class.

This paper reports the results relative to the link class 3 . These values are the ones reported in the scatterplot of Figure 4, By observing them, it emerges that they lie in the stable region of the curve. Therefore, the linear specification of the speed-density curve is calibrated:

$$
\mathrm{v}=v(\beta v(\mathrm{k}, \mathrm{q}), \mathrm{k})=\mathrm{v}_{0}+\beta \times \mathrm{k}
$$

The values of the calibrated parameters are:

- $\quad$ free speed $\mathrm{v}_{0}=72.55(\mathrm{~km} / \mathrm{h})$;

- $\quad$ speed reduction per unit of density $\beta=-1.65(\mathrm{~km} /$ veic $\times \mathrm{km} / \mathrm{h})$. 


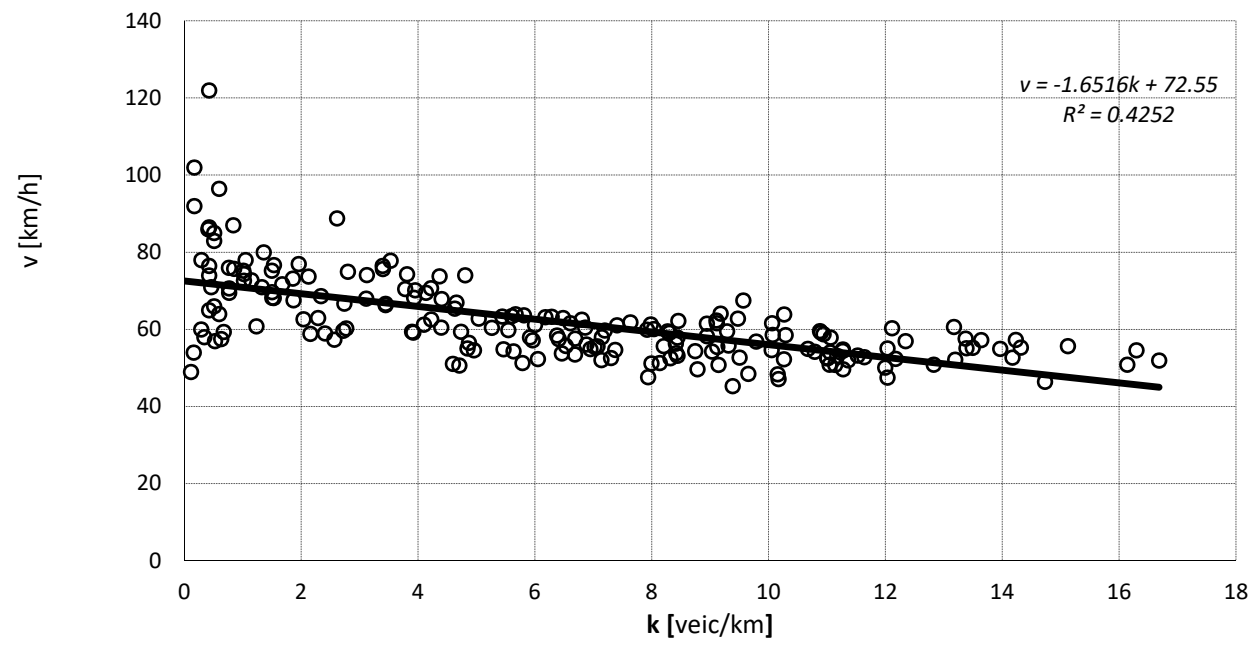

Figure 4. Speed-density scatterplot and speed-function for a link of class 3.

The same procedure can be adopted for all link categories.

As far as concerns acceleration functions, the values of acceleration, $\beta_{\mathrm{a} 1}$ and $\beta_{\mathrm{a} 2}$, are estimated directly from the observed frequency of accelerations of FCD detected on the link of class c (Figure $5 a, b)$.

\section{Class 3}

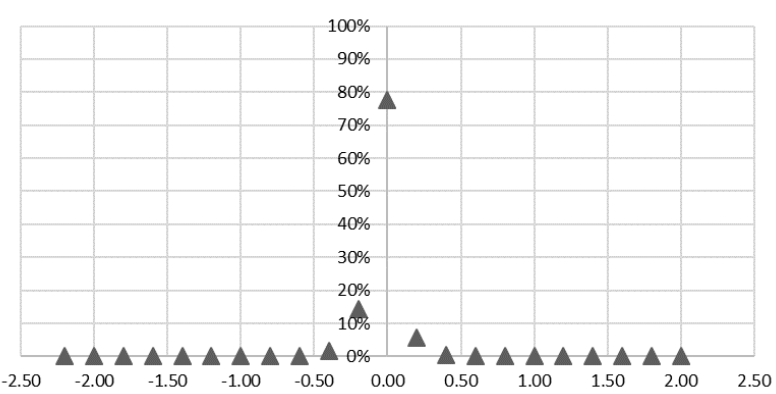

(a)

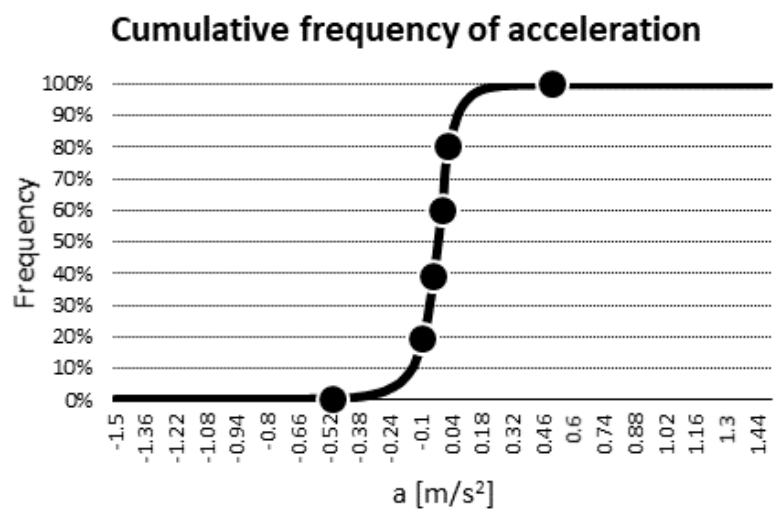

(b)

Figure 5. Relative (a) and cumulative (b) frequency of FCD vehicle accelerations for one link class, considered as an example ([4]).

Figure $5 a, b$ depict, as an example, the relative (a) and cumulative (b) frequencies of vehicle accelerations for one link class, considered as example (it could be extended to the other identified link classes), of the available FCD. The calibrated average acceleration, $\beta_{\mathrm{a} 1}$ and $\beta_{\mathrm{a} 2}$.

\subsubsection{Probe EV Experimentation}

The experimental data relating to energy consumption are obtained by means of probe EVs, equipped with:

- GPS devices, to detect the position and kinematic characteristics of the vehicle: instantaneous speed, direction with respect to geographic north; 
- on-board computer, capable of recording energy consumption: propulsion energy and recovered energy.

The fully electric vehicle has travelled along routes that, starting from the port, reach some touristic destinations within the study area. Figure 6 reports the itinerary of one route, composed of a group of paths, having as origin the Porto delle Grazie.

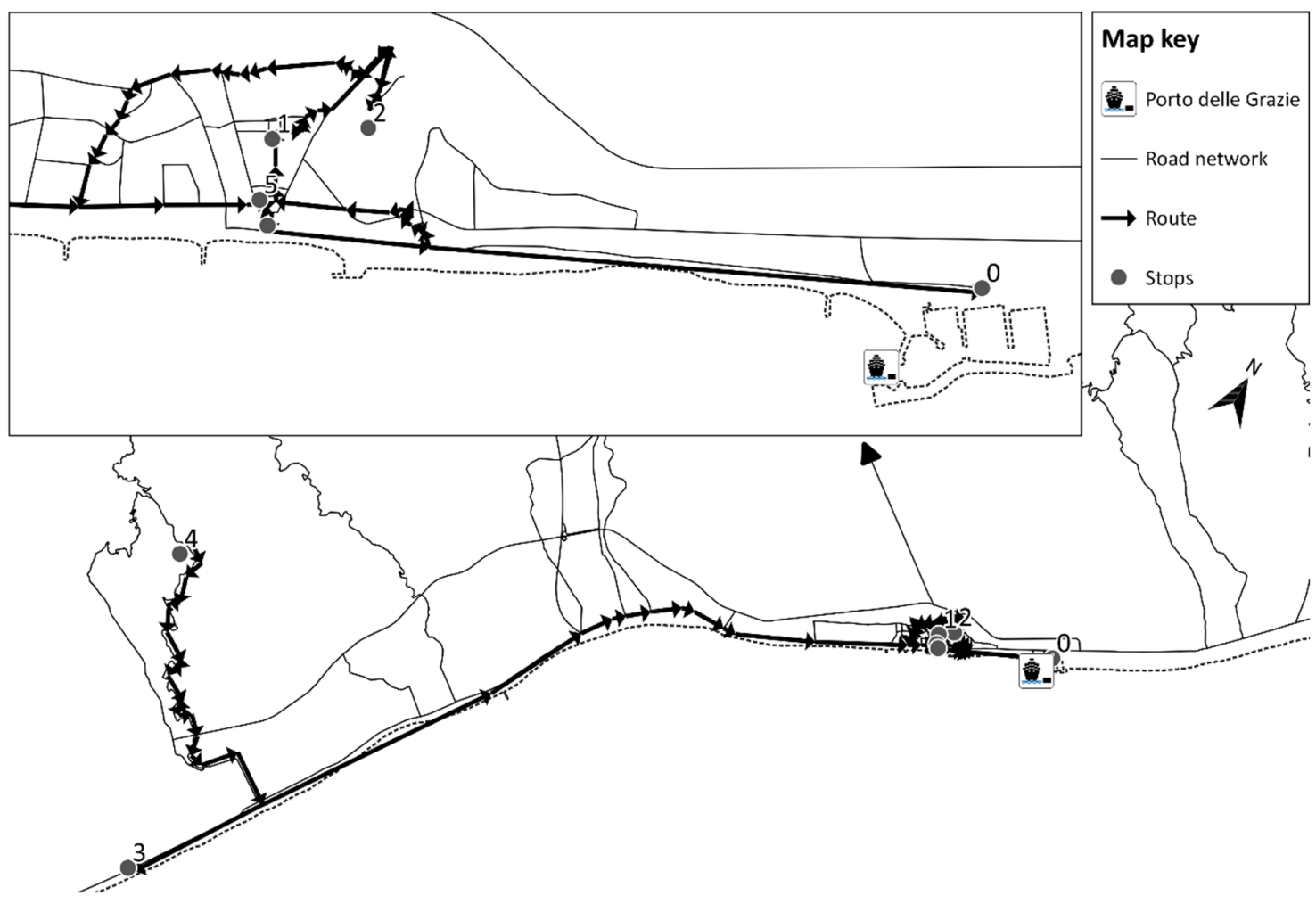

Figure 6. Example of route analysed.

Experimental data about energy consumption from the probe EVs made it possible to measure the amount of electricity consumed and recovered along the paths, which compose the route travelled by the vehicle.

\section{Calibration of Vector $\beta$}

The experimental data about the position and the kinematic characteristics of the probe EVs made it possible to update the speed functions parameters, $\beta_{\mathrm{V}}$, and of the acceleration functions, $\beta_{\mathrm{a}}$, previously estimated with FCD on each link of the network (Section 4.2.1).

As far as concerns speeds, the value of speed on the link, $\beta_{\mathrm{v} 1}$, is updated from the direct measurement of the instantaneous speed of the probe EVs, if equipped vehicle passed the link; otherwise, it is updated from FCD, if no equipped vehicle did not travel on the link.

As far as concern accelerations, the values of acceleration, $\beta_{\mathrm{a} 1}$ and $\beta_{\mathrm{a} 2}$, are updated from the direct observation of accelerations of the probe EVs passing the link (Figure 7a,b and Table 3).

Figure $7 \mathrm{a}, \mathrm{b}$ depict, as an example, the updated relative (a) and cumulative (b) frequencies of vehicle accelerations for link class 3 , measured by the probe EVs passing on the link. The updated values of acceleration for each link class are reported in Table 3 . The portions of the link in which the acceleration could be positive, negative, and zero are also updated from the frequency diagram of accelerations of Figure 7a,b (Table 3). 


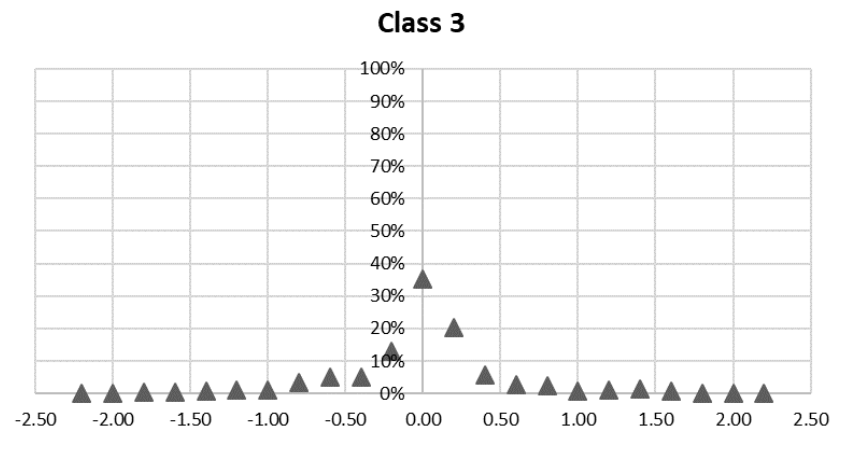

(a)

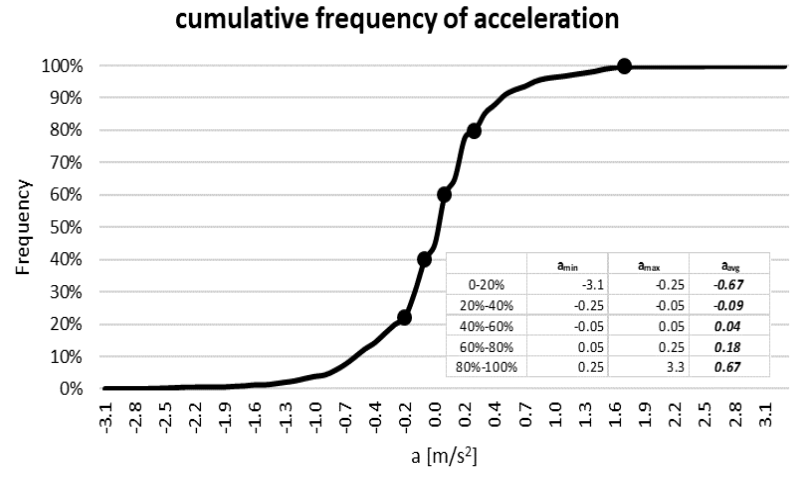

(b)

Figure 7. Updated relative (a) and cumulative (b) frequency of equipped vehicle accelerations for link class 3.

Table 3. Updated parameters of vector $\beta$ for each link class c.

\begin{tabular}{cccccc}
\hline & $\boldsymbol{\beta}_{\mathbf{v} \mathbf{2}}$ & $\boldsymbol{\beta}_{\mathbf{v} \mathbf{3}}$ & $\boldsymbol{\beta}_{\mathbf{v} \mathbf{4}}$ & $\boldsymbol{\beta}_{\mathbf{a} \mathbf{1}}(>\mathbf{0})$ & $\boldsymbol{\beta}_{\mathbf{a} \mathbf{2}}(<\mathbf{0})$ \\
\hline class c & $\mathbf{( 1 / \mathbf { m } )}$ & $\mathbf{( 1 / \mathbf { m } )}$ & $\mathbf{( 1 / m )}$ & $\left(\mathbf{m} / \mathbf{s e c}^{\mathbf{2}}\right)$ & $\left(\mathbf{m} / \mathbf{s e c}^{\mathbf{2}}\right)$ \\
\hline 1 & 0.397 & 0.206 & 0.397 & 0.15 & -0.27 \\
2 & $0.06^{(*)}$ & $0.83^{(*)}$ & $\left.0.11^{*}\right)$ & 0.23 & -0.32 \\
3 & 0.401 & 0.198 & 0.401 & 0.32 & -0.38 \\
4 & 0.400 & 0.202 & 0.398 & 0.51 & -0.55 \\
5 & 0.409 & 0.202 & 0.389 & 0.49 & -0.63 \\
\hline
\end{tabular}

(*) Parameters calibrated with FCD data (Table 2).

Finally, the above operations allow to update allow to obtain a second-round updating of a vector $\beta$, by considering the cinematic data obtained by the probe EVs. The calibration was executed considering Equations (10) and (11), assuming the weights in the objective function equal to zero.

The results of the further updating of vector $\beta$, executed by applying the optimization model (Equation (3)), is reported in Table 3 (except for links of class 2 for which there are no available data), where the observed values of speeds (vector $v^{*}$ ) are experimentally measured on probe EVs travelling on the defined paths.

By comparing the two calibrated sub-vectors of speed parameters, $\beta_{\mathrm{v} 2}, \beta_{\mathrm{v} 3}$ and $\beta_{\mathrm{v} 4}$, with FCD (Table 2) and with probe EVs (Table 3) experimentations, it emerges that the percentage of link in which the vehicles, on average, travel at constant speed, $\beta_{\mathrm{v} 3}$ (Figure 3), reduces from the FCD experimentation to the probe EVs one. The result of the calibration with probe EVs is more in line with the observed phenomenon, where the speed of individual vehicles is always variable while travelling along the link. The higher value of parameter $\beta_{\mathrm{v} 3}$ in FCD experimentation is due to the fact that the spatio-temporal "distance" from two consecutive FCD points is relevant (one kilometre, or one minute) in the examined case.

\section{Calibration of Vector $\gamma$}

The calibrated parameters $\gamma$ are reported in Table 4. The calibration was executed considering the Equation (11), assuming the weights in the objective function equal to zero and using a double-stage calibration process. 
Table 4. Calibration results of vector of parameters $\gamma$.

\begin{tabular}{|c|c|c|c|c|c|c|c|c|}
\hline \multicolumn{2}{|c|}{ Model } & \multirow{2}{*}{$\begin{array}{l}1^{*} \\
\text { All }\end{array}$} & \multirow{2}{*}{$\begin{array}{c}2 \\
\text { All }\end{array}$} & \multicolumn{2}{|c|}{$3 *$} & \multicolumn{3}{|c|}{$4^{*}$} \\
\hline \multirow{3}{*}{$\begin{array}{l}\text { Parameters } \\
\text { (first stage) }\end{array}$} & Link class & & & $1-4$ & 5 & $1-2$ & $3-4$ & 5 \\
\hline & $\gamma_{\mathrm{rt}}$ & 1.409 & 1.209 & 1.230 & 1.676 & 1.770 & 1.109 & 1.752 \\
\hline & $\gamma_{\text {in }}$ & 1.409 & 1.492 & 1.230 & 1.676 & 1.770 & 1.109 & 1.752 \\
\hline \multirow{3}{*}{$\begin{array}{l}\text { Parameters } \\
\text { (second stage) }\end{array}$} & Link class & All & All & \multicolumn{2}{|c|}{ All } & \multicolumn{3}{|c|}{ All } \\
\hline & $\gamma_{\mathrm{w}-\mathrm{b}}$ & 0.661 & 0.642 & \multicolumn{2}{|c|}{0.654} & \multicolumn{3}{|c|}{0.653} \\
\hline & $\gamma_{\mathrm{t}-\mathrm{w}}$ & 0.904 & 0.878 & \multicolumn{2}{|c|}{0.895} & \multicolumn{3}{|c|}{0.893} \\
\hline
\end{tabular}

${ }^{*}$ constrained to: $\gamma_{\mathrm{rt}}=\gamma_{\text {in }}$; o.f. $=$ objective function.

For all models:

- $\quad$ the first stage minimization process concerns the calibration of the two parameters $\gamma_{\mathrm{rt}}$ and $\gamma_{\text {in, }}$, related to the levels of energy consumed, $e()$;

- the second stage minimization process concerns the calibration of the parameter $\gamma_{\mathrm{t}-\mathrm{w}}$, related to the tank-to-wheels efficiency, and of the parameter, $\gamma_{\mathrm{w}-\mathrm{b}}$, related to the wheels-to-battery regenerative efficiency.

As far as concerns the first stage minimization process, models 1, 3 and 4 assume the constrain that the parameter of total resistances is equal to the parameter of inertial force: $\gamma_{\mathrm{rt}}=\gamma_{\mathrm{in}}$ (Equation (3)). In model 1 the calibrated value of the parameter is $\gamma_{\mathrm{rt}}=\gamma_{\mathrm{in}}=1.409$ and it is the same for the five link classes defined above (Section 4.2.1). Model 3 presents two calibrated values of parameter, $\gamma_{\mathrm{rt}}=\gamma_{\mathrm{in}}$, for two groups of link classes: $\gamma_{\mathrm{rt}}=\gamma_{\mathrm{in}}=1.230$ for group of classes 1, 2, 3 and $4 ; \gamma_{\mathrm{rt}}=\gamma_{\mathrm{in}}=1.676$ for class 5 . Model 4 is the most disaggregate one in terms of link class representation; it presents three calibrated values of parameter $\gamma_{\mathrm{rt}}=\gamma_{\mathrm{in}}$ for three groups of link classes: $\gamma_{\mathrm{rt}}=\gamma_{\mathrm{in}}=1.770$ for group of classes 1 and 2; $\gamma_{\mathrm{rt}}=\gamma_{\mathrm{in}}=1.109$ for group of classes 3 and $4 ; \gamma_{\mathrm{rt}}=\gamma_{\mathrm{in}}=1.752$ for class 5. Model 2 does not consider the constrain $\gamma_{\mathrm{rt}}=\gamma_{\mathrm{in}}$; therefore, $\gamma_{\mathrm{rt}}=1.209$ is the calibrated value for the total resistances and $\gamma_{\text {in }}=1.492$ is the calibrated value for inertial force. The two parameters are the same for the five link classes defined above (Section 4.2.1). As general comment, in all the four models the calibrated parameters are greater than 1 , due to the fact that the values of estimated consumed energy are lower, on average, than the corresponding experimental values for each path (Figure 8a).

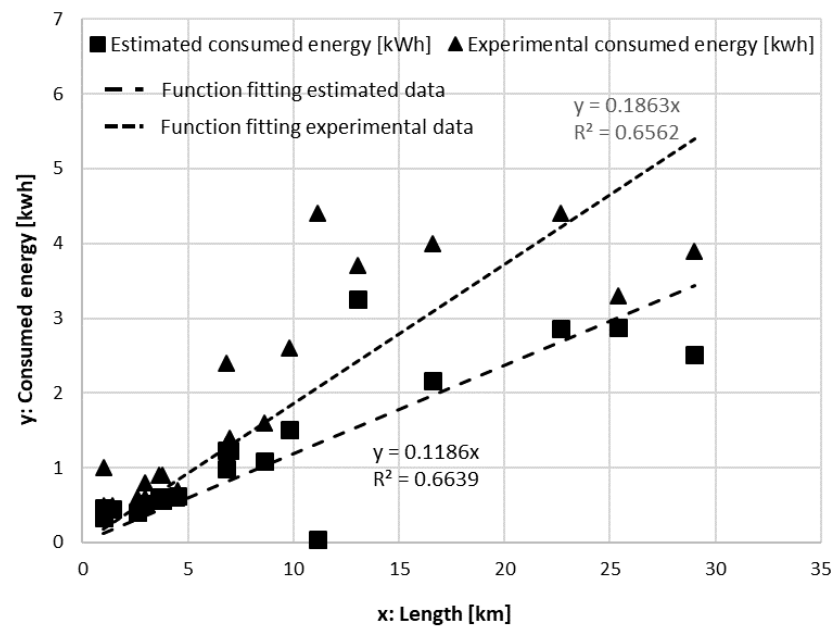

(a)

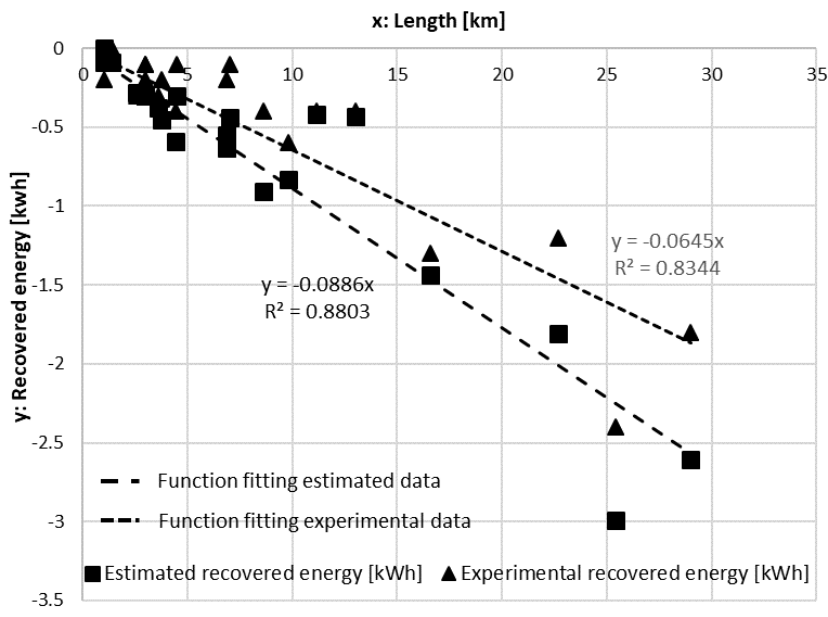

(b)

Figure 8. Estimated energy consumption with parameters of literature and experimental energy consumption with probe EVs vs. path length: consumed energy (a) and recovered energy (b). 
As far as concerns the second stage minimization process, in all the models the calibrated parameters $\gamma_{\mathrm{t}-\mathrm{w}}$ and $\gamma_{\mathrm{w}-\mathrm{b}}$ are valid for all the five link classes. They are less than one, confirming their nature of efficiency terms. The calibrated parameter related to the wheels-to-battery regenerative efficiency, $\gamma_{\mathrm{w}-\mathrm{b}}$, ranges from 0.642 and 0.661 because the values of estimated recovered energy are higher, on average, that the corresponding experimental values for each path (Figure $8 b$ ). The value of the calibrated parameter, $\gamma_{\mathrm{w}-\mathrm{b}}$, is inside the range of values (between 0.59 and 0.84) estimated in the literature; and it is close to the mean value of 0.69 among all the individual values.

\subsection{Validation}

The validation of the proposed framework relates to energy consumption models (calibration of vector $\gamma^{\mathrm{T}}$ ), and it is based upon the following data:

- estimated values of energy consumption and energy recovery of EVs with parameters of literature (Figure 8);

- observed values of energy consumption and energy recovery of probe EVs (Figure 9);

- validation statistics of the models: initial and final values of objective functions and of rho-square (Table 5);

- estimated values of energy consumption and energy recovery with calibrated parameters (Figure 9);

- disaggregated estimated energy consumption of EVs along a route (Figure 10).

Table 5. Validation statistics.

\begin{tabular}{ccccc}
\hline Model & $\mathbf{1}^{*}$ & $\mathbf{2}$ & $\mathbf{3}^{*}$ & $\mathbf{4}^{*}$ \\
\hline Initial objective function & 24.31 & 24.31 & 24.31 & 24.31 \\
Final objective function & 6.30 & 5.95 & 5.50 & 4.88 \\
$\varrho^{2}$ & 0.741 & 0.755 & 0.774 & 0.799 \\
\hline
\end{tabular}

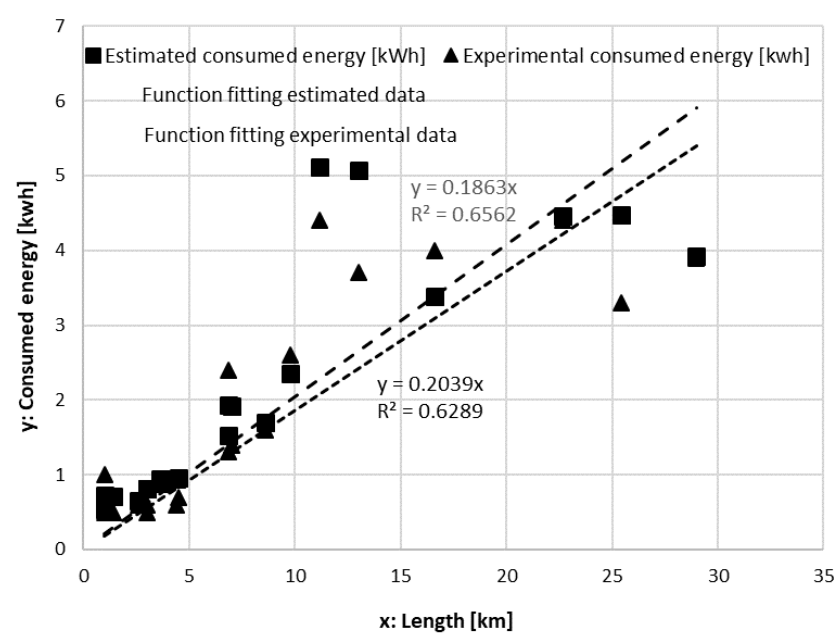

(a)

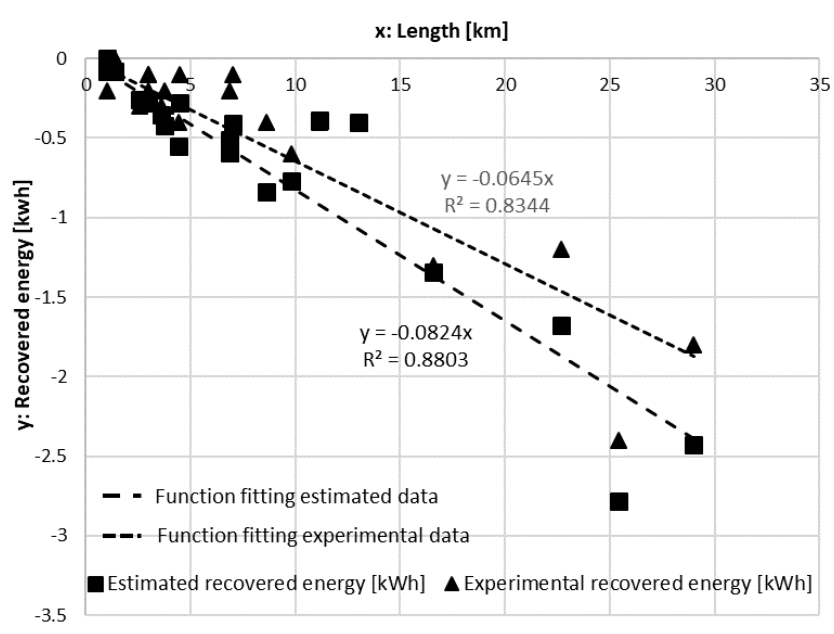

(b)

Figure 9. Estimated energy consumption and experimental energy consumption vs. path length: consumed energy (a) and recovered energy (b). 


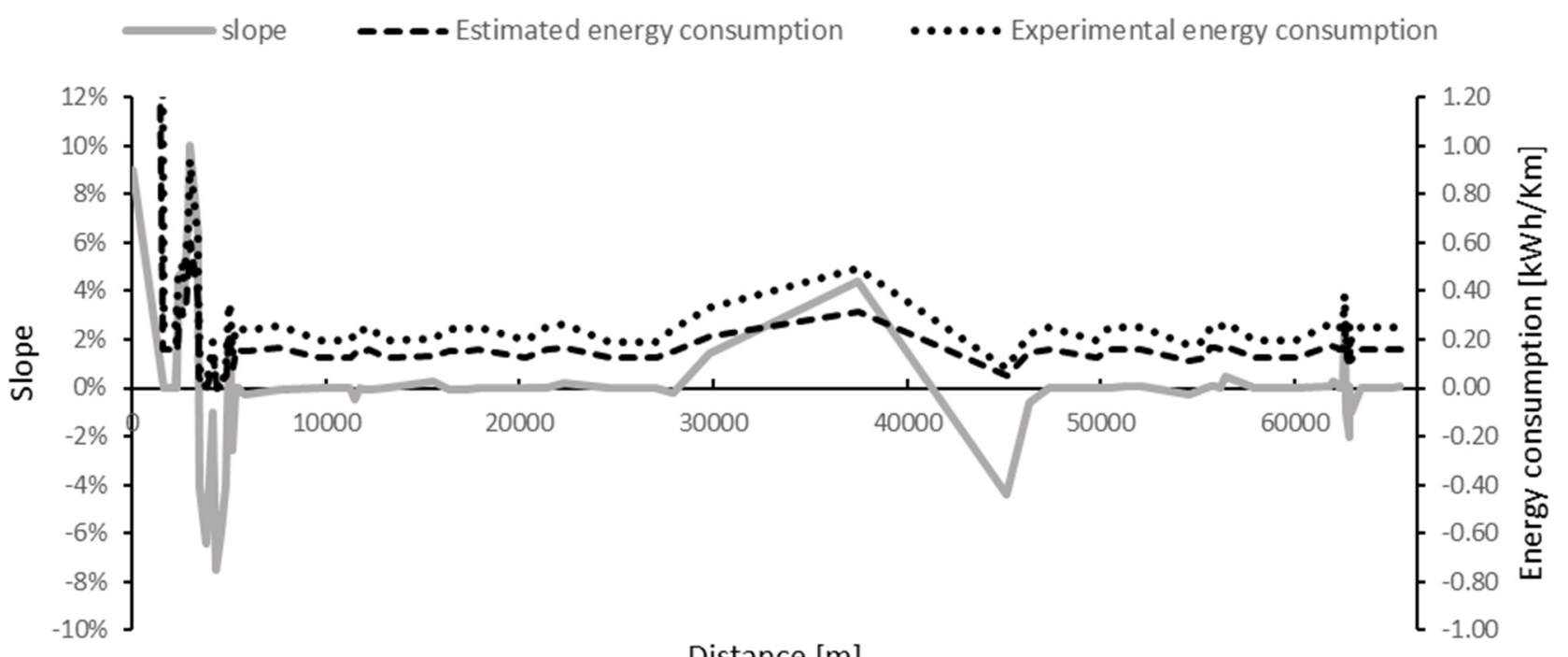

Distance $[\mathrm{m}]$

Figure 10. Comparison of disaggregated estimation of energy consumption (with literature parameters) and of estimation of energy consumption (with calibrated parameters of model 1).

Figure $8 \mathrm{a}, \mathrm{b}$ shows the scatterplots between estimated energy consumption with parameters of literature vs. path length and between experimental energy consumption with probe EVs vs. path length. In particular, Figure 8a reports the scatterplot between estimated and experimental consumed energy vs. path length and two calibrated linear models: (a) the estimated energy consumption per unit of distance and (b) the experimental energy consumption per unit of distance. For model (a), the estimated coefficient is $0.1186(\mathrm{kwh} / \mathrm{km})$ (value of $R^{2}=0.6434$ ), while for model (b), it is $0.1863\left(\mathrm{kwh} / \mathrm{km}\right.$ ) (value of $\mathrm{R}^{2}=0.6562$ ).

By using parameters of literature, the energy consumption of EVs is underestimated of $63 \%$. Figure $8 \mathrm{~b}$ reports the scatterplot between estimated and experimental recovered energy vs. path length and two calibrated linear models: (a) the estimated energy recovered per unit of distance and (b) the experimental energy recovered per unit of distance. For model (a), the estimated coefficient is $-0.0886(\mathrm{kwh} / \mathrm{km})$ (value of $\left.R^{2}=0.88\right)$; while for model (b), it is $-0.0645(\mathrm{kwh} / \mathrm{km})$ (value of $\left.R^{2}=0.83\right)$. In this case, the energy consumption of EVs is overestimated of $27 \%$. The discrepancy between estimated and experimental energy consumption may be probably derived from the increased efficiency of the observed vehicles, during the experimentation described in the paper, with respect the vehicles observed in the past and considered for the calibration of the literature values. Since the "estimated" is based on ICEV data, this means that ICEV is less efficient than the EV tested in this study.

Table 5 shows the values of objective function (o.f.) and of $\rho^{2}$ statistics related to the estimated models. They improve by passing from the less disaggregated model in terms of link classes (model 1: one parameter) to the most disaggregated one (model 4: three parameters).

As an example of model validation, the new scatterplots of the energy consumed and recovered estimated with model 1 vs. paths length are obtained (Figure 9ab). In particular, Figure 9a reports the new scatterplot of the energy consumed estimated with model 1 vs. path length and the corresponding calibrated linear model. The estimated coefficient of the linear model is $0.2039(\mathrm{kwh} / \mathrm{km})$ (value of $\left.R^{2}=0.62\right)$, with a gain in the prediction capability of the model 1 respect to the prediction in the first level minimization process. Figure $9 \mathrm{~b}$ reports the new scatterplot of the energy recovered estimated with model $1 \mathrm{vs.}$ path length and the corresponding calibrated linear model. The estimated coefficient of the linear model is $-0.0824(\mathrm{kwh} / \mathrm{km})$ (value of $\left.R^{2}=0.88\right)$, with a (reduced) gain in the prediction capability of the model 1 respect to the first level minimization process. 
The last validation result concerns the disaggregate representation at link level of energy consumption per unit of distance $(\mathrm{kwh} / \mathrm{km})$ along the route travelled of an $\mathrm{EV}$, composed of several paths considered in the experimentation (the route is depicted in Figure 6). The route presents the following relevant characteristics:

- the most part (44 km, which are the $66 \%$ of the total route length) has no relevant changes of slope both inside urban and extra-urban areas;

- a part (5 km, which are the $8 \%$ of the total route length) has relevant changes of slope (up to $10 \%$ in ascent and up to $-8 \%$ in descent), close to the urban area of Roccella Jonica;

- a part (17 km, which are the $26 \%$ of the total route length) has changes of slope in extra-urban area (necessary to the EV to reach the village of Gerace, located at $373 \mathrm{mt}$ of altitude).

The pattern of energy consumption per unit of distance in estimated with parameters of literature and estimated with calibrated parameters (with the application of model 1) is depicted in Figure 10. The figure also reports the pattern of slope variation (\%), in order to highlight the peaks of energy consumption of EV in the portions of the route with highest variation of slope. The mass of the driver is not considered, and this could concur to determine the difference. In the case of estimation with calibrated parameters (model 1), the level of consumed energy is higher respect to the case of parameters of literature.

\section{Conclusions and Research Perspectives}

This paper aimed to calibrate (or update) parameters of traffic flow and energy consumption models of EVs by means of big-data (FCD) and experimental (probe vehicles) data.

The ICT tools and applications in mobility and automotive markets (e.g., mobile phones, GPSs, on-board vehicles equipment) allow the collection of a huge amount of potentially valuable information on travel patterns, transport networks and energy consumption of road vehicles. Their use (FCD), combined with experimental data (obtained by means of probe EVs), could lead to relevant benefits in terms of updating the traditional parameters of energy consumption models for EVs, estimated in the past for ICEVs. The benefits are two-fold:

- the increasing capacity to analyse and forecast the effect of the increasing number of EVs with respect to the road traffic conditions, geometry-related characteristics and drivers' behaviour;

- the minimization of costs necessary to build the above models by combining big-data and experimental data.

The paper could be considered as an example of validation of traffic flow and energy consumption models in a real context, updating previous and/or literature model specification and parameters values. This aim is to verify if, and in what amount, the existing parameters of resistances/energy consumptions model calibrated in the literature for ICEVs change for EVs, in order to obtain updated parameters. The results of the calibration process presented in the paper are encouraging, as they allow to updating parameters related to the energy consumption and to the energy recovering terms of EVs. The latter term is relevant in EVs, which is more evident on urban routes, where drivers experience unstable traffic conditions (stop-and-go), rather than on extra-urban routes, where drivers travel in more stable traffic conditions (constant speed).

The effect of temperature on energy consumption has not been considered, as the experimentation took place during a limited period with rather constant temperature. It is well known that temperature has a strong effect on energy consumption and this element will be further investigated.

The updated parameters of EVs energy consumption could be to be used for future eco-driving and eco-routing applications. The minimum travel time has been traditionally considered by transport planners and analysts as the main important criterion in path 
and route choice on a road network. While reducing fuel consumption was considered a secondary objective, as in most situations, the minimum travel time and minimum fuel consumption criteria were consistent for ICEV users.

Methods and models presented in this paper can be useful for different stakeholders involved in EV's market, as producers or consumers. The calibrated functions can be adopted for evaluating investments in the electrification of the vehicle fleet. In general, proposed models support the activities of mobility management.

The introduction of EVs in the market needs the criteria connected to path and route choices, and their potential impacts on traffic assignment when the penetration of EVs in the market will increase, to be re-defined and further investigated.

In the future, the experimentations can be extended to an entire private or public vehicle fleet in order to analyse interactions between user behaviour, EVs and road infrastructure.

Author Contributions: A.I.C.: Formal analysis, Data curation. G.M.: Conceptualization, Methodology, Formal analysis, Investigation, Writing-Review and Editing. C.R.: Data curation, validation, Investigation. A.V.: Supervision, Conceptualization, Formal analysis, Methodology. All authors have read and agreed to the published version of the manuscript.

Funding: This research is partially supported by the Dipartimento di ingegneria dell'Informazione, delle Infrastrutture e dell'Energia Sostenibile, Università Mediterranea di Reggio Calabria, and by the project "La Mobilità per i passeggeri come Servizio-MyPasS", Fondi PON R\&I 2014-2020 e FSC “Avviso per la presentazione di Progetti di Ricerca Industriale e Sviluppo Sperimentale nelle 12 aree di Specializzazione individuate dal PNR 2015-2020", codice identificativo ARS01_01100.

Institutional Review Board Statement: Not applicable.

Informed Consent Statement: Not applicable.

Data Availability Statement: The data presented in this study are partially available on request. The data are not publicly available due to privacy restrictions.

Conflicts of Interest: The authors declare no conflict of interest.

\section{List of Acronyms}

$\begin{array}{ll}\text { C } & \text { Calibration } \\ \text { CDR } & \text { Call Detail Record } \\ \text { EC } & \text { Energy Consumption } \\ \text { EV } & \text { Electric Vehicle } \\ \text { FCD } & \text { Floating Car Data } \\ \text { GLS } & \text { Generalized Least Square } \\ \text { GPS } & \text { Global Positioning System } \\ \text { ICEV } & \text { Internal Combustion Engines Vehicle } \\ \text { ICT } & \text { Information and Communication Technology } \\ \text { POI } & \text { Point Of Interests } \\ \text { S } & \text { Specification } \\ \text { SCV } & \text { Specification-Calibration-Validation } \\ \text { TF } & \text { Traffic Flow } \\ \text { TS } & \text { Transport Supply } \\ \text { TD } & \text { Travel Demand } \\ \text { TSM } & \text { Transport System Model } \\ \text { V } & \text { Validation }\end{array}$

\section{References}

1. Banister, D. Sustainable Transport: Challenges and Opportunities. Transportmetrica 2007, 3, 91-106. [CrossRef]

2. United Nations. Mobilizing Sustainable Transport for Development. Analysis and Policy Recommendations from United Nations Secretary-General's High-Level Advisory Group on Sustainable Transport. 2016. Available online: https://smartnet.niua.org/ content/dba21324-6ccc-42fd-b44a-7d61df6cb34e (accessed on 21 December 2021).

3. Bonnel, P.; Munizaga, M.A. Transport survey methods in the era of big data facing new and old challenges. Transp. Res. Procedia 2018, 32, 1-15. [CrossRef] 
4. Croce, A.I.; Musolino, G.; Rindone, C.; Vitetta, A. Transport system models and big data: Zoning and graph building with traditional surveys, FCD and GIS. ISPRS Int. J. Geo-Inf. 2019, 8, 187. [CrossRef]

5. $\quad$ Lee, R.J.; Sener, I.N.; Mullins, J.A. Emerging Data Collection Techniques for Travel Demand Modeling: A Literature Review Final Report Texas A\&M Transportation Institute: College Station, TX, USA, 2014.

6. Cascetta, E. Transportation Systems Analysis. Models and Applications; Springer: New York, NY, USA, 2009.

7. Guo, D.; Liu, S.; Jin, H. A graph-based approach to vehicle trajectory analysis. J. Locat. Based Serv. 2010, 4, 183-199. [CrossRef]

8. Oloo, F. Mapping Rural Road Networks from Global Positioning System (GPS) Trajectories of Motorcycle Taxis in Sigomre Area, Siaya County, Kenya. ISPRS Int. J. Geo-Inf. 2018, 7, 309. [CrossRef]

9. Xu, L.; Yue, Y.; Li, Q. Identifying urban traffic congestion pattern from historical Floating Car Data. Procedia Soc. Behav. Sci. 2013, 96, 2084-2095. [CrossRef]

10. Pirra, M.; Diana, M. Integrating mobility data sources to define and quantify a vehicle-level congestion indicator: An application for the city of Turin. Eur. Transp. Res. Rev. 2019, 11, 41. [CrossRef]

11. Wang, J.; Wang, X.; Kostyniuk, L. Using GPS Data to Understand Driving Behaviour. J. Urban. Technol. 2008, 15, 33-53.

12. Nuzzolo, A.; Comi, A.; Papa, E.; Polimeni, A. Understanding Taxi Travel Demand Patterns Through Floating Car Data. In Data Analytics: Paving the Way to Sustainable Urban Mobility. CSUM 2018. Advances in Intelligent Systems and Computing; Nathanail, E., Karakikes, I., Eds.; Springer: Cham, Switzerland, 2019; Volume 879, pp. 445-452.

13. Zhang, Y.; Owen, L.E.; Clark, J.E. A Multi-Regime Approach for Microscopic Traffic Simulation; 78th Annual Meeting; Transportation Research Board: Washington, DC, USA, 1999.

14. Alonso, B.; Ibeas, A.; Musolino, G.; Rindone, C.; Vitetta, A. Effects of traffic control regulation on Network Macroscopic Fundamental Diagram: A statistical analysis of real data. Transp. Res. Pol. Pract. 2019, 12, 136-151. [CrossRef]

15. Ortuzar, J.; Willumsen, L.G. Modelling Transport, 3rd ed.; Wiley: Chichester, UK, 2001.

16. Vitetta, A. A quantum utility model for route choice in transport systems. Travel Behav. Soc. 2016, 3, 29-37. [CrossRef]

17. Peeta, S.; Ziliaskopoulos, A.K. Foundations of dynamic traffic assignment: The past, the present and the future. Netw. Spat. Econ. 2001, 1, 233-265. [CrossRef]

18. Shaukata, N.; Khana, B.; Alia, S.M.; Mehmooda, C.A.; Khana, J.; Farida, U.; Majidb, M.; Anwarc, S.M.; Jawadd, M.; Ullaha, Z. A survey on electric vehicle transportation within smart grid system. Renew. Sustain. Energy Rev. 2018, 81, 1329-1349. [CrossRef]

19. Calise, F.; Liberato Cappiello, F.; Cartenì, A.; Dentice d'Accadia, M.; Vicidomini, M. A novel paradigm for a sustainable mobility based on electric vehicles, photovoltaic panels and electric energy storage systems: Case studies for Naples and Salerno (Italy). Renew. Sustain. Energy Rev. 2019, 111, 97-114. [CrossRef]

20. Leonori, S.; Rizzoni, G.; Frattale Mascioli, F.M.; Rizzi, A. Intelligent energy flow management of a nanogrid fast charging station equipped with second life batteries. Int. J. Electr. Power Energy Syst. 2021, 127, 1066. [CrossRef]

21. Travesset-Baro, O.; Rosas-Casals, M.; Jover, E. Transport energy consumption in mountainous roads. A comparative case study for internal combustion engines and electric vehicles in Andorra. Transp. Res. Part D 2015, 34, 16-26. [CrossRef]

22. Gupta, S.; Deshpande, S.R.; Tulpule, P.; Canova, M.; Rizzoni, G. An Enhanced Driver Model for Evaluating Fuel Economy on Real-World Routes. IFAC-Pap. Line 2019, 52, 574-579. [CrossRef]

23. Gupta, S.; Canova, M. Eco-Driving of Connected and Autonomous Vehicles with Sequence-to-Sequence Prediction of Target Vehicle Velocity. IFAC-Pap. Line 2021, 54, 430-436. [CrossRef]

24. Zhang, J.; Lu, X.; Xue, J.; Li, B. Regenerative braking system for series hybrid electric city bus. World Electr. Veh. J. 2008, 2, 128-134. [CrossRef]

25. Gao, D.W.; Mi, C.; Emadi, A. Modeling and simulation of electric and hybrid vehicles. Proc. IEEE 2007, 95, 729-745. [CrossRef]

26. Wu, X.; Freese, D.; Cabrera, A.; Kitch, W.A. Electric vehicles' energy consumption measurement and estimation. Transp. Res. Part D 2015, 34, 52-67. [CrossRef]

27. Zhang, R.; Yao, E. Electric vehicles' energy consumption estimation with real driving condition data. Transp. Res. Part D Transp. Environ. 2015, 41, 177-187. [CrossRef]

28. Cantarella, G. Sistemi di Trasporto: Tecnica e Economia; UTET: Turin, Italy, 2009; ISBN 10-8859802083.

29. Croce, A.I.; Musolino, G.; Rindone, C.; Vitetta, A. Energy consumption of electric vehicles: Models' estimation using big data (FCD). In Proceedings of the Transport Research Procedia: 22nd EURO Working Group on Transportation Meeting, EWGT 2019, Barcelona, Spain, 18-20 September 2019. 